\title{
Self-Affirmation through WeChat Moments
}

\author{
Xiangli Wen, Yaozhong Liu, Yakun Ni \\ School of Management, Jinan University, Guangzhou, China \\ Email: meko_wen@yeah.net
}

How to cite this paper: Wen, X. L., Liu, Y. Z., \& Ni, Y. K. (2019). Self-Affirmation through WeChat Moments. Psychology, 10, 371-383.

https://doi.org/10.4236/psych.2019.103026

Received: January 28, 2019

Accepted: February 19, 2019

Published: February 22, 2019

Copyright (c) 2019 by author(s) and Scientific Research Publishing Inc. This work is licensed under the Creative Commons Attribution International License (CC BY 4.0).

http://creativecommons.org/licenses/by/4.0/

\begin{abstract}
Self-affirmation is helpful for reducing the individual's defensive response to threats, harvesting and growing from threatening but valuable information. This study examines whether viewing personal WeChat moments is self-affirmative. Browsing WeChat moments of other people that better than yourself will lead to an upward social comparison, but the effect of browsing your own moments is rarely discussed. This study conducts an experiment, and the result proves that browsing WeChat moments is an effective self-affirmation intervention paradigm. The self-affirmation paradigm which is close to daily life deserves further promotion and research.
\end{abstract}

\section{Keywords}

Self-Affirmation, WeChat, Moments

\section{Introduction}

The core idea of self-affirmation is that people may try to cope with self-threat by affirming the self-domain that is not related to threats (Steele, 1975). One of the most important ways to affirm yourself is to explore one's core values, which in turn may lead to changes in attitudes, cognitive performance, and behavior (Wen, Butler, \& Koutstaal, 2013). Using social networks has become a part of people's lives. People are used to publishing their own photos, videos, texts or forwarding corresponding links in a circle of friends to present themselves. People's self-presentation on social networks includes positive presentation and real presentation. Individuals will emphasize their abilities and advantages, or share their life. After an individual presents himself, he will also receive feedbacks from friends, more often, it is positive feedback. In this way, individuals interact with their friends and deepen their relationships. According to the self-affirmation theory, focusing on self-worth and getting positive feedback from others is a source of self-affirmation. Previous studies have found that the 
participants viewing their own Facebook profile page can bring about the same effect as the previous laboratory's self-affirmation manipulation. This study will use WeChat as a new self-affirmation intervention paradigm to explore whether it can produce a self-affirming effect consistent with Facebook.

\subsection{Self-Affirmation Theory}

The premise of self-affirmation theory is that people have incentives to maintain self-integrity (Aronson, Cohen, \& Nail, 1999; Sherman \& Cohen, 2002; Steele, 1988). Integrity means that an individual is a person who is kind and appropriate (behaves appropriately in a certain cultural context) in general. Therefore, the standard of self-integrity differs in various cultural backgrounds, groups and scenes (Heine, 2005).

The incentive or motivation to maintain self-integrity has three import characteristics:

1) Motivation is a general statement of oneself as a good and appropriate individual, instead of a specific self-concept. Self-affirmation is flexible, and individuals can focus on their own positive realities and build a solid foundation for self-completeness (Dunning, 2005). Self-affirmation mainly affirms individual's positive and excellent self-worth.

2) The motivation for self-completeness is not superior or excellent, but "sufficiently good", so individual's self-affirmation does not need to pursue comparison with others and become the best, as long as it reaches a level of satisfaction.

3) The motivation for self-completeness is not to praise yourself, but to act in a manner that deserves respect or praise. If self-affirmation lacks credibility, it may yield counterproductive results (Wood, Perunovic, \& Lee, 2010). Therefore, the resources of self-affirmation must be real, not fictional and beautiful self-illusions.

Self-completeness is a sense of overall efficacy. It is the self-image that individuals can control their important adaptive and moral outcomes in life. The threat to this image raises a psychological threat (Steele, 1988; Sherman \& Cohen, 2006). There are many forms of threats to self-integrity, but they always cause real and perceived failure of the individual. When integrity is threatened, the motivation to protect self-completeness may lead to defensive reactions such as defensive bias, although defensive bias can restore self-integrity, rejection of threat information can reduce the likelihood that the person will learn from potentially important information.

At this time, people can respond to threats by affirming the indirect psychological adaptation of alternative self-resources that are not related to threats. This is a different psychological adaptation proposed by the self-affirmation theory, and in many cases it can restore self-integrity. This self-affirmation involves focusing on important aspects of the individual's self-worth that are not related to the threat, or participating in activities that are not related to the threat. When people affirm themselves in this way, they realize that their 
self-worth does not depend on the current situation being evaluated, and there is no longer a need to distort provocative threats to respond to threat information in a more open and fair manner. When individuals can cope with threats in this way, it means that self-affirmation has an effect, which often as a means of testing the effectiveness of self-affirmation.

Self-affirmation can bring a range of beneficial effects, such as reducing stress. Self-affirmative subjects can solve creative problems under more stress (Creswell et al., 2013), enhance creativity (de Buisonjé, Ritter, Bruin, Horst, \& Meeldijk, 2017), and improve students' problem-solving ability under chronic stress (Creswell, Dutcher, Klein, Harris, \& Levine, 2013). Self-affirmation also reduces defensive effects, making it easier to accept valuable information or increase your awareness of the ability to handle problems. Such as increasing health-related behaviors (such as promoting the consumption of vegetables and fruits) (Fielden, Sillence, Little, \& Harris, 2016; Epton \& Harris, 2008), increasing compassion and prosocial behavior (Lindsay \& Creswell, 2014). Increased pro-environmental behavior, self-affirmation group relative to the control group of participants will increase the intention of recycling behavior (Sparks, Jessop, Chapman, \& Holmes, 2011). It is precisely because self-affirmation has many beneficial values for individuals, so it is of great significance to expand self-affirmation research and practical application.

\subsection{Self-Affirmative Experimental Manipulation}

The most used self-affirmation intervention paradigm in research is to give people the opportunity to briefly write down personal core values, such as social relationships (McQueen \& Klein, 2006; Napper et al., 2009). Personal values are the intrinsic standard for individuals to evaluate themselves (Rokeach, 1973). Participants will look at a list of values, then choose one or more values that are the most important to them, and then write an essay explaining why the chosen values are important to them. In addition to laboratory manipulation, many daily activities can be self-affirming: play with friends (Cohen \& Sherman, 2014), buy luxury items (Sivanathan \& Pettit, 2010) or check out their Facebook page (Toma \& Hancock, 2013).

With regard to the timing of maneuvers, ideally, self-affirmation should occur at the moment when psychological threats occur and when resources are readily available to mitigate threats (Cohen, Garcia, \& Goyer, 2017). If a psychological threat has occurred and been resolved, the impact of self-affirmation is limited. If resources are difficult to obtain, the positive intentions generated by self-affirmation are unlikely to be used for action (Ferrer \& Cohen, 2018). Studies have shown that self-affirmation introduced before threat feedback reduces defensive responses (Critcher, Dunning, \& Armor, 2010).

Since the research paradigm for self-worth affirmation in previous studies is too monotonous and rarely used in daily life, the effect cannot be separated from the laboratory situation. Therefore, this study will follow the research results of 
Toma (Toma \& Hancock, 2013) and will manipulate self-affirming by viewing WeChat personal moments. This research is aimed at examining that viewing personal moments on WeChat also has the same self-affirmation effect in China's situation.

\subsection{Self-Affirmation Effect of WeChat Personal Moments}

According to the elements of the self-affirmation theory in previous articles, does the WeChat personal moments meet the self-affirmation criteria?

First, a key aspect of affirmative intervention is that its content is self-generated and suitable for mining each person's specific value identity (Sherman, 2013). Studies have shown that self-presentation in social networking sites can meet individual self-presentation needs (Krmer \& Winter, 2008; Hofmann \& Nadkarni, 2012; Yao, Ma, Yan, \& Chen, 2014). WeChat's self-presentation involves showing many aspects of an individual: social roles, attitudes and preferences, and most importantly, social connections with friends and family. In fact, the latter has been identified as the most powerful source of self-affirmation (Sherman \& Cohen, 2006). After posting a status in the friends' circle, you may receive comments and likes from your friends. When a person gets positive feedback from others and reflects on their positive aspects, it may trigger a process of self-affirmation (Sherman \& Cohen, 2006).

Second, the self-presentation of self-affirmation should be positive and ideal. Self-presentation on the website may be malleable, and individuals are more controlled in a social networking environment than in face-to-face everyday situations, and can selectively and strategically present themselves (Ellison, Heino, \& Gibbs, 2006). Individuals can selectively publish or upload information that helps shape a positive personal image that is positively self-presenting (Kim \& Lee, 2011). Compared to face-to-face communication, online self-presentation and relationship interactions are more easily controlled, leaving more positive information (Anna \& Herbert, 2017).

Finally, the self-presentation information of self-affirming must be accurate. WeChat friends are mainly friends and family members in real relationships. In important relationships, individuals have the pressure of real self-presentation. If individuals are eager to establish intimate relationships, the desire to be understood and supported by friends will encourage them to be open and honest rather than deceptive self-presentation (Ellison, Heino, \& Gibbs, 2006). Since social networking sites are primarily based on the characteristics of acquaintances (Ellison, Steinfield, \& Lampe, 2007), individuals try to present real information (Yang, 2014) for true self-presentation.

In general, WeChat personal moments have the potential to give individuals a self-affirming value. Toma and Hancock (2013) have found that Facebook's profiles have a self-affirming effect, and the effect is no different from traditional self-affirming manipulation. This study will further verify this part of the WeChat function. 


\subsection{Present Study}

The previous literature analysis shows that WeChat personal moments content meets the criteria of self-affirmation. Self-affirmation needs to meet three conditions: the emergence of psychological threats, the existence of available resources, and the timeliness of certainty (Ferrer \& Cohen, 2018). In this study, fictitious IQ test results will be used as the source of the individual's upward comparison threat. IQ test is an important personal value threat for most individuals, especially for college students. WeChat personal moments content as a self-affirmation availability resource, the experimental group to view their own WeChat personal moments, the control group to view their friends' personal moments, and affirm themselves before being threatened.

This study assumes that viewing WeChat personal moments can reduce the individual's defensive response caused by the upward threat, and play a self-affirming effect. According to the hypothesis, individuals who have viewed their own WeChat personal moments are more accepting of IQ test results, and are less likely to derogate this test.

\section{Study}

\subsection{Purposes}

As mentioned earlier, social networking platforms provide new ways to express self and self-worth areas (such as relationships, values), and the large-scale use of social networks provides an opportunity to test self-affirmation theories in a new environment. Because social networks are ubiquitous and easy to access, we are able to investigate the operation of self-affirmation in people's own environment and daily life, providing important extensions to existing research. Main research in the past mainly using artificial self-affirmation exercises (McQueen \& Klein, 2006), the effect of using WeChat for self-affirmation has not been repeatedly verified.

This experiment explores whether the WeChat personal moments can play a self-affirming effect from the behavioral level. In the experiment, a threat situation will be constructed. The stimulus material is an abstract painting. Participants in this experiment are all non-art college students or students who have studied painting, and exclude the influence of personal factors on the experimental manipulation effect. After receiving the threat information, if the defensive effect of the subject (self-affirmation group) who viewed the WeChat personal moments is lower than the subject (control group) who views the others' WeChat personal moments, it is proved that the action of viewing the WeChat personal moments content is performed. It does have a self-affirming effect.

\subsection{Methods}

\subsubsection{Participants}

This study publishes recruitment information through the WeChat group in the 
Jinan University. Students can voluntarily sign up for the experiment. After the experiment, all participants can get 20 yuan experimental reward. A total of 63 participants were recruited, they don't receive professional painting training before, and all subjects had normal or corrected visual acuity, no neurological or mental medical history, and signed informed consent before the experiment. Two participants were excluded from the analyses because they didn't complete the defensive effect test questionnaire in the experiment. The effective sample size was thus reduced to $N=61$ ( $M$ age $=21.36, S D=2.89,14$ males and $47 \mathrm{fe}-$ males).

\subsubsection{Experimental Manipulation}

\section{1) Upward Comparative Threat Manipulation}

The first research draws on Crawford's (2007) manipulation of current mission performance, accessing information about the relative position of the self and the comparison object, constructing immediate potential surrounding characters to stimulate the threat situation of the upward comparison. The experimental guidance for threat manipulation is: "The current experiment is to verify the latest research results abroad. This study shows that people need to first collect important information hidden in the picture and then integrate it. With processing, and finally making decisions, this series of processes can reflect the differences in the level of intelligence of different people.

Next, an abstract picture will appear randomly on the screen. Two appearances at a time, a total of 40 pictures. The experimental task is to determine which of the two images has a higher collection value (more coordinated in brightness, color or content). The answer speed is not included in the score statistics, you can carefully compare and complete the selection within 5 minutes (including the time to read this guide). If a person can be sensitive to the difference between the two pictures and quickly make the correct value judgment, the better the score, the higher his intelligence level (Han \& Chi, 2012)". The test materials are all abstract prints downloaded from the Internet. They are various in style and appear randomly in the options.

After the subject has completed the picture test, the computer screen will present false feedback on the results to the participants, all the participants receive their own scores and rankings: "Your correct selection rate for this picture is: $7 / 20=35 \%$. As of now, we have tested 30 people and your score is currently ranked 27th". The contrast feedback can directly perceive the information of the performance of the upward comparison object, and the information intensity of the commonly used upward comparison standard is strong.

\section{2) Self-Affirmation Manipulation}

In the conditional group of WeChat self-affirmation $(n=32)$, the participants used 5 minutes to browse WeChat personal moments (click on his own avatar entry). The instruction is: "The staff is counting the scores of your test results. The ranking takes about 5 minutes. During this period, please complete a WeChat user experience study. You can use 5 minutes to browse 'Moments' (click 
on your own avatar to enter), you can browse any elements inside, Including your own published content (photos, videos, text, and forwarded links, etc.), like information and comment information, but only browse your own content, be careful not to quit to chat and browse other people's moments. Because after 5 minutes, you need to answer some user experience questions about WeChat content". No self-affirmation group $(n=29)$ would choose the first friend of the WeChat friends list, and took 5 minutes to browse his/her "personal moments" (click on their avatar to enter), if the friend sets the visible days limit, then choose the next friend.

\subsubsection{Procedure}

The experiment claims to recruit participants for the purpose of "IQ test tools and WeChat user experience perfection". Participants were randomly assigned to two groups and the experiments were performed separately. There are five steps of the experiment: accept the IQ test, browse the "personal photo album" to complete the self-affirmation manipulation, complete the user experience test questionnaire, inform the score and ranking to complete the inter-group threat manipulation, complete the threat manipulation test and the defensive effect test questionnaire.

At the beginning, the participants needed to sign the experimental informed consent form, understand the purpose and steps of the experiment, as well as the individual's rights and obligations, and collect personal information. After the purpose of the experiment is explained, the subjects are emphasized to calculate their scores after they complete the picture test, giving them the number of correct pictures and the correct rate. Next, let the subjects choose the one with higher collection value (or the one that is more harmonious in brightness, color and content) in the two abstract pictures randomly appearing on the computer screen. A total of 40 pictures. After the subject has completed the picture test, the computer screen will display "The staff is counting the scores of your test results. It takes about 5 minutes. During this time, please return to the group and follow the instructions to complete the test 2: WeChat's user experience test", and then the participants began to browse WeChat personal photo album.

In order to ensure good surface validity, after the 5 minutes browsing time, the participants will complete 5 questions about WeChat user experience (the results are not included in the statistics), and then answer the relevant situation of WeChat use. The results of the IQ test were then given to the participants, all of which were negative feedback. The subjects were then asked to answer the threat manipulation test and the defensive effect test questionnaire.

After the experiment, the participants were asked whether they could guess the purpose of the experiment. All the subjects failed to guess, which proved that the experimental design had good surface validity and successfully concealed the purpose of self-affirmation. After the experiment is completed, we explain the purpose of the experiment to the participants, and explain the falseness of the material to eliminate the threat. 


\subsubsection{Measures}

\section{1) User Experience Test Questionnaire}

In order to maintain good surface validity, the participants were asked to evaluate the WeChat experience after viewing the WeChat personal album. But the score is not included in the final statistics. Items include: WeChat icons and fonts are designed to meet aesthetic needs; WeChat's button settings are easy to operate; WeChat uses more fast response; WeChat checkpoints and comments are more convenient; WeChat pictures can meet the needs. Using Likert 5 points to score, 1 very agrees, 5 very disagree.

\section{2) Threat Manipulation Effect Test}

The subjects need to evaluate the results based on two questions. "I know very well about the results of my picture test", 5 points, 1-very disagree to 5 -very agree. "Do you think is this feedback positive?" Result is a 9-point scale score, the lower the score, the more negative the answer is to the subject. Through these two questions, the threat scenario is checked and the participants are clear about their achievements and the results are negative, which proves that the manipulation of the threat scenario is effective.

\section{3) Defensive Effects Test Questionnaire}

Adapted from the defensive effect measurements of Toma \& Hancock (2013), the participants will answer three items (How accurate do you think the results are?; Do you agree with the test result?; Do you agree that this test result will have some value for you?). 5 points scoring, all topics are scored in reverse, the higher the score, the higher the defensive effect of the subject. The Cronbach's a coefficient of the defensive effect term in this study was .84.

\subsection{Results}

\subsubsection{Threat Maneuver Validity Test}

Fully aware of their own performance and perceived negative feedback can prove that the threat situation is effective. As shown in Table 1, an independent sample $t$ test of the score understanding, the results show that the self-affirmation group's score and the control group's score have no significant difference, $t(59)$ $=.68, p=.50>.05, d=.17$.

An independent sample $t$ test was performed on the feedback positivity judgment. As presented in Table 1, it was found that there was no significant difference between the feedback positivity judgment of the self-affirmation group and the control group, $t(59)=1.60, p=.11>.05, d=.41$. And the feedback positivity was judged as negative $(M=4.12, S D=1.67)$, which proved that threat manipulation is effective.

Table 1. Threat maneuver validity test result in each group.

\begin{tabular}{ccccc}
\hline & \multicolumn{2}{c}{ score understanding } & \multicolumn{2}{c}{ feedback positivity judgment } \\
\cline { 2 - 5 } & $M$ & $S D$ & $M$ & $S D$ \\
\hline self-affirmation group & 3.56 & 1.29 & 4.44 & 1.68 \\
control group & 3.35 & 1.20 & 3.76 & 1.62 \\
\hline
\end{tabular}




\subsubsection{Defense Response Difference Test}

An independent sample t-test for self-affirmation (self-affirmation, comparison) was designed with the defense response as the dependent variable. The results, as presented in Table 2 below, showed that the self-affirmation effect was significant, and the defense of the self-affirmation group was significantly different from that of the control group, $t(59)=-2.31, p=.02<.05, d=-.59$.

Consistent with the behavioral results of previous studies (Toma \& Hancock, 2013), this study found that individuals who viewed their WeChat personal moments within 5 minutes were less likely to blame others and question accuracy when receiving negative feedback from the test. This non-defensive attitude towards self-threat is a sign of self-affirmation (Steele, 1988) and provides compelling evidence that viewing WeChat personal moments content adds to self-worth and self-integrity. These findings suggest that spending time on social networks may satisfy important self-fulfillment: WeChat enhances users' perceptions of self-worth by demonstrating an attractive, successful and embedded self-image of a meaningful social network.

\section{Discussion}

This study achieved results consistent with the published research (Toma \& Hancock, 2013), and proved the self-affirmation effect of WeChat's personal moments. Self-affirming resources are rich and diverse, such as family relationships, and relationships with intimate partners. However, the self-affirmation manipulation methods in previous studies are mainly self-value affirmation, relatively single, and difficult to promote to other fields. In the past studies, self-affirmation interventions always complete the examination and emphasis of self-values in laboratory conditions, however, these self-affirmation methods are not consistent with the information that people will encounter in daily life, but deliberate and non-daily self-affirmation interventions. Because of the deliberate nature, subjects may guess the intention and the self-affirmation effect would be influenced (Sherman et al., 2009). These perceptions of intentions will undermine self-affirmation because of external forced completion rather than personal choice (Silverman, Logel, \& Cohen, 2013). Viewing WeChat's personal moments is a relatively natural way to meet people's daily behavior. When people are free, they open WeChat to review some of their previous statuses, see the interactions with friends, and re-capture strength from social relationships. None of the participants in the study realized that the intention of viewing WeChat's personal moments, which means this self-affirmation was not easy to detect and more in line with the premise that self-affirmation worked.

Table 2. Defense response test result in each group.

\begin{tabular}{ccc}
\hline & \multicolumn{3}{c}{ defense response } \\
\cline { 2 - 3 } & $M$ & $S D$ \\
\hline self-affirmation group & 3.24 & .76 \\
control group & 3.68 & .72 \\
\hline
\end{tabular}


Memories of self-worth are sometimes difficult to trace, but the state and messages left in a personal album sometimes remind the individual of important moments that have been forgotten. The true positive self-presentation of individuals on WeChat will affect their gains from social networks. It is found that the true self-presentation of social networking sites directly affects the frequency of individuals receiving positive feedback from social networking sites, and individuals who perform real self-presentation will promptly tell your friends about your situation and get more online positive feedbacks (Yang, 2014) and social supports (Kim \& Lee, 2011). These positive feedbacks and social supports are inherently important sources of self-affirmation. Exploring personal moments is undoubtedly reinforcing this part of self-worth.

As mentioned before, the threatened self-domain (intelligence test) is different from the enhanced field (WeChat self-presentation), and decoupling the threatened self-domain from the affirmative field is a necessary condition for self-affirmation theory. As the self-affirmation theory claims, self-affirmation is an indirect process. Implicit self-esteem compensation occurs automatically when a person's self-worth is threatened and does not involve any specific activity.

This experimental procedure satisfies the requirements for self-affirmation manipulation in previous studies and has achieved remarkable results. Our experiment uses the defensive reduction paradigm of the self-affirmation effect, which is the gold standard in the field, and proves that the personal moments content browsing in WeChat reduces the defense against self-threat.

The research result is a further development on the research of relationship between the use of social networking sites and individual psychosocial adaptation, and deepens the research of influence mechanism of self-affirmation. Our research will play a role in promoting the controversial research on the value of self-affirmation which scholars discussed on social networks in recent times. More refined, previous studies have studied the impact of the upward comparison on the mental health of individuals in the circle of friends. The focus of this study is the individual's ability to browse the content of his own friends in the circle of friends has a beneficial impact and provides direction for how to use social networks in the future.

It is necessary to repeat this research findings in future work, and further study the impact of browsing WeChat personal moments on users. Since this is a way of self-affirmation, it can test the psychological impact of existing self-affirmation, including the improvement of self-conceptual clarity (Waksiak \& Trope, 2009) and the increase of self-resources (Schmeichel \& Vohs, 2009).

The subjects recruited in this study are basically college students and graduate students. Although this group is currently the main group used by WeChat, it needs to be cautious when promoting the influence of other groups. For example, for the people those only forward links, less likely to publish themselves, or interact less with friends, will it be effective to browse the WeChat moments? This requires further research in the future. 


\section{Conclusion}

This study found that viewing WeChat personal moments can be used as an effective intervention paradigm for self-affirmation. Compared with individuals who view their friends' WeChat personal moments, individuals who view their own WeChat personal moments have less defensive responses when faced with upward threats.

\section{Conflicts of Interest}

The authors declare no conflicts of interest regarding the publication of this paper.

\section{References}

Anna, M., \& Herbert, S. (2017). The long-Term Benefits of positive Self-Presentation via Profile Pictures, Number of Friends and the Initiation of Relationships on Facebook for Adolescents' Self-Esteem and the Initiation of Offline Relationships. Frontiers in Psychology, 8, 1981. https://doi.org/10.3389/fpsyg.2017.01981

Aronson, J., Cohen, G., \& Nail, P. R. (1999). Self-Affirmation Theory: An Update and Appraisal. Sankhya, 104, 127-147.

Cohen, G. L., \& Sherman, D. K. (2014). The Psychology of Change: Self-Affirmation and Social Psychological Intervention. Annual Review of Psychology, 65, 333-371. https://doi.org/10.1146/annurev-psych-010213-115137

Cohen, G. L., Garcia, J., \& Goyer, J. P. (2017). Turning Point: Targeted, Tailored, and Timely Psychological Intervention. In A. Elliot, C. Dweck, \& D. Yeager (Eds.), Handbook of Competence and Motivation, Second Edition: Theory and Application (pp. 657-686). New York, NY: Guilford Press.

Crawford, M. T. (2007). The Renegotiation of Social Identities in Response to a Threat to Self-Evaluation Maintenance. Journal of Experimental Social Psychology, 43, 39-47. https://doi.org/10.1016/j.jesp.2005.12.011

Creswell, J. D., Dutcher, J. M., Klein, W. M. P., Harris, P. R., \& Levine, J. M. (2013). Self-Affirmation Improves Problem-Solving under Stress. PLoS One, 8, e62593. https://doi.org/10.1371/journal.pone.0062593

Critcher, C. R., Dunning, D., \& Armor, D. A. (2010). When Self-Affirmations Reduce Defensiveness: Timing Is Key. Personality and Social Psychology Bulletin, 36, 947-959. https://doi.org/10.1177/0146167210369557

de Buisonjé, D. R., Ritter, S. M., Bruin, S. D., Horst, J. M. L. T., \& Meeldijk, A. (2017). Facilitating Creative Idea Selection: The Combined Effects of Self-Affirmation, Promotion Focus and Positive Affect. Creativity Research Journal, 29, 174-181. https://doi.org/10.1080/10400419.2017.1303308

Dunning, D. (2005). Self-Insight: Roadblocks and Detours on the Path to Knowing Thyself. New York: Psychology Press. https://doi.org/10.4324/9780203337998

Ellison, N. B., Steinfield, C., \& Lampe, C. (2007). The Benefits of Facebook "Friends": Social Capital and College Students' Use of Online Social Network Sites. Journal of Computer-Mediated Communication, 12, 1143-1168. https://doi.org/10.1111/j.1083-6101.2007.00367.x

Ellison, N., Heino, R., \& Gibbs, J. (2006). Managing Impressions Online: Self-Presentation Processes in the Online Dating Environment. Journal of Computer-Mediated Communication, 11, 415-441. 
https://doi.org/10.1111/j.1083-6101.2006.00020.x

Epton, T., \& Harris, P. R. (2008). Self-Affirmation Promotes Health Behavior Change. Health Psychology, 27, 746-752. https://doi.org/10.1037/0278-6133.27.6.746

Ferrer, R. A., \& Cohen, G. L. (2018). Reconceptualizing Self-Affirmation with the Trigger and Channel Framework: Lessons from the Health Domain. Personality and Social Psychology Review, In Press. https://doi.org/10.1177/1088868318797036

Fielden, A. L., Sillence, E., Little, L., \& Harris, P. R. (2016). Online Self-Affirmation Increases Fruit and Vegetable Consumption in Groups at High Risk of Low Intake. Applied Psychology Health \& Well-Being, 8, 3-18. https://doi.org/10.1111/aphw.12059

Han, X. Y., \& Chi, Y. K. (2012). The Self-Threat of Unsolicited Social Comparison and Its Balance. Journal of Psychology, 44, 1628-1640.

Heine, S. J. (2005). Constructing Good Selves in Japan and North America. In R. M. Sorrentino, D. Cohen, J. M. Olson, \& M. P. Zanna (Eds.), Cultural and Social Behavior: The Ontario Symposium (Vol. 10, pp. 95-116). Mahwah, NJ: Lawrence Erlbaum Associates.

Hofmann, S. G., \& Nadkarni, A. (2012). Who Do People Use Facebook? NIH Public Access, 52, 243-249.

Kim, J., \& Lee, J. E. R. (2011). The Facebook Paths to Happiness: Effects of the Number of Facebook Friends and Self-Presentation on Subjective Well-Being. CyberPsychology, Behavior, and Social Networking, 14, 359-364.

Krmer, N. C., \& Winter, S. (2008). Impression Management 2.0. Journal of Media Psychology, 20, 106-116.

Lindsay, E. K., \& Creswell, J. D. (2014). Helping the Self Help Others: Self-Affirmation Increases Self-Compassion and Pro-Social Behaviors. Frontiers in Psychology, 5, 421. https://doi.org/10.3389/fpsyg.2014.00421

McQueen, A., \& Klein, W. M. P. (2006). Experimental Manipulations of Self-Affirmation: A Systematic Review. Self \& Identity, 5, 289-354. https://doi.org/10.1080/15298860600805325

Napper, L., Harris, P. R., \& Epton, T. (2009). Developing and Testing a Self-Affirmation Manipulation. Self \& Identity, 8, 45-62. https://doi.org/10.1080/15298860802079786

Rokeach, M. (1973). The Nature of Human Values. In The Nature of Human Values and Value Systems (pp. 5-11). New York: Free Press.

Schmeichel, B. J., \& Vohs, K. (2009). Self-Affirmation and Self-Control: Affirming Core Values Counteracts Ego Depletion. Journal of Personality and Social Psychology, 96, 770-782. https://doi.org/10.1037/a0014635

Sherman, D. K. (2013). Self-Affirmation: Understanding the Effects. Social \& Personality Psychology Compass, 7, 834-845. https://doi.org/10.1111/spc3.12072

Sherman, D. K., \& Cohen, G. L. (2002). Accepting Threatening Information: Self-Affirmation and the Reduction of Defensive Biases. Current Directions in Psycho-logical Science, 11, 119-123. https://doi.org/10.1111/1467-8721.00182

Sherman, D. K., \& Cohen, G. L. (2006). The Psychology of Self-Defense: Self-Affirmation Theory. Advances in Experimental Social Psychology, 38, 183-242.

Sherman, D. K., Cohen, G. L., Nelson, L. D., Nussbaum, A. D., Bunyan, D. P., \& Garcia, J. (2009). Affirmed Yet Unaware: Exploring the Role of Awareness in the Process of Self-Affirmation. Journal of Personality and Social Psychology, 97, 745-764.

https://doi.org/10.1037/a0015451

Silverman, A., Logel, C., \& Cohen, G. L. (2013). Self-Affirmation as a Deliberate Coping Strategy: The Moderating Role of Choice. Journal of Experimental Social Psychology, 
49, 93-98. https://doi.org/10.1016/j.jesp.2012.08.005

Sivanathan, N., \& Pettit, N. C. (2010). Protecting the Self Through Consumption: Status Goods as Affirmational Commodities. Journal of Experimental Social Psychology, 46, 564-570. https://doi.org/10.1016/j.jesp.2010.01.006

Sparks, P., Jessop, D. C., Chapman, J., \& Holmes, K. (2011). Pro-Environmental Actions, Climate Change, and Defensiveness: Do Self-Affirmations Make a Difference to People's Motives and Beliefs about Making a Difference? British Journal of Social Psychology, 49, 553-568. https://doi.org/10.1348/014466609X471976

Steele, C. M. (1975). Name-Calling and Compliance. Journal of Personality and Social Psychology, 31, 361-369. https://doi.org/10.1037/h0076291

Steele, C. M. (1988). The Psychology of Self-Affirmation: Sustaining the Integrity of the Self. Advances in Experimental Social Psychology, 21, 261-302. https://doi.org/10.1016/S0065-2601(08)60229-4

Toma, C. L., \& Hancock, J. T. (2013). Self-Affirmation Underlies Facebook Use. Personality \& Social Psychology Bulletin, 39, 321-331.

https://doi.org/10.1177/0146167212474694

Waksiak, C., \& Trope, Y. (2009). Cognitive Consequences of Affirming the Self: The Relationship between Self-Affirmation and Object Construal. Journal of Experimental Social Psychology, 45, 92-932.

Wen, M. C., Butler, L. T., \& Koutstaal, W. (2013). Improving Insight and Non-Insight Problem Solving with Brief Interventions. British Journal of Psychology, 104, 97-118. https://doi.org/10.1111/j.2044-8295.2012.02107.x

Wood, J. V., Perunovic, W. Q., \& Lee, J. W. (2010). Positive Self-Statements: Power for Some, Peril for Others. Psychological Science, 20, 860-866. https://doi.org/10.1111/j.1467-9280.2009.02370.x

Yang, C. C. (2014). It Makes Me Feel Good: A Longitudinal, Mixed-Methods Study on College Freshmen's Facebook Self-Presentation and Self-Development. Doctoral Dissertation, Madison, WI: University of Wisconsin-Madison.

Yao, Q., Ma, H. W., Yan, H., \& Chen, Q. (2014). Analysis of Social Network Users' Online Behavior from the Perspective of Psychology. Advances in Psychological Science, 22, 1647. https://doi.org/10.3724/SP.J.1042.2014.01647 